\title{
The dispersal ability of wood cricket (Nemobius sylvestris) (Orthoptera: Gryllidae) in a wooded landscape
}

\author{
Niels C. BROUWERS ${ }^{1}$, Adrian C. NEWTON ${ }^{2}$ and SALLIE BAILEY ${ }^{3}$
}

\author{
${ }^{1}$ State Centre of Excellence for Climate Change, Woodland and Forest Health, School of Environmental Science, Murdoch \\ University, 90 South Street, Murdoch, 6150, Western Australia; e-mail: n.brouwers@murdoch.edu.au; ncbrouwers@hotmail.com \\ ${ }^{2}$ School of Conservation Sciences, Bournemouth University, Talbot Campus, Fern Barrow, Poole, Dorset, BH12 5BB, UK \\ ${ }^{3}$ Corporate and Forestry Support, Forestry Commission, Silvan House, 231 Corstorphine Road, Edinburgh, EH12 7AT, UK
}

Key words. Gryllidae, Nemobius sylvestris, dispersal ability, woodland, forest, population spread, landscape, habitat network

\begin{abstract}
Information on the dispersal ability of flightless insect species associated with woodlands is severely lacking. Therefore, a study was conducted examining the dispersal ability of wood cricket (Nemobius sylvestris) juveniles (nymphs) and adults in a wooded landscape on the Isle of Wight, UK, to further our understanding of the ecology and management of this and other flightless insects. A series of experiments were conducted where nymphs and adults were released and observed at a range of spatial-temporal scales within different habitat environments. The results of this investigation indicated no difference in the dispersal ability of wood cricket nymphs and adults. However, adult females moved less than adult males. Adult males were found to spread twice as fast as females, and males were found capable of traversing up to $55 \mathrm{~m}$ away from woodland habitat through semi-natural and grazed grassland. Additionally, rates of population spread of both wood cricket nymphs and adults (males and females) were found to be accurately described by the inverse-power function, predicting only few individuals dispersing over time. Together this indicates that overall colonization success and rate of population spread, being female dependent, is likely to be low for this species. Wood crickets were found to live in and able to move along mature woodland edges directly bordering agricultural land. This indicates that conservation initiatives focusing on creating woodland corridors and developing woodland habitat networks have the potential to facilitate the spread and population viability of wood crickets, if the woodland edges are given enough time to develop. However, long-term monitoring is needed to evaluate the overall effectiveness of such approaches.
\end{abstract}

\section{INTRODUCTION}

Dispersal is widely considered to be a key process influencing the survival of populations of species within fragmented landscapes (Hanski \& Gilpin, 1997; Kindvall, 1999; Turner et al., 2001; Fahrig, 2003; Diekötter et al., 2005; Ranius, 2006). However, the dispersal ability (i.e. speed and distance over time) of many groups of species is poorly known (Dolman \& Fuller, 2003; Ranius, 2006). Investigations of specific dispersal strategies using experiments undertaken at fine spatio-temporal scales can provide valuable initial insights into the dispersal ability of species (Turchin, 1991, 1998; Samu et al., 2003; Brouwers \& Newton, 2010b). However, dispersal typically takes place over large scales (Levin, 1992) and therefore needs to be examined across a range of spatiotemporal scales (Brouwers \& Newton, 2010b). Deriving reliable estimates of dispersal in natural environments represents an ongoing challenge, but is highly important in terms of understanding population dynamics and predicting species persistence within the landscape (Turchin, 1998; Trakhtenbrot et al., 2005; Nathan, 2008).

Few studies have examined the dispersal ability of relatively immobile invertebrate species that are grounddwelling and move by walking (Diekötter et al., 2005; Diekötter et al., 2010). Compared to flying invertebrates, such species move over finer scales, and may therefore be considered more vulnerable to habitat fragmentation
(Tscharntke et al., 2002; Diekötter et al., 2005). However, most dispersal studies of ground-dwelling invertebrates have focused on species associated with open seminatural grassland habitats (e.g. Vermeulen, 1994; Baur et al., 2005; Öckinger \& Smith, 2008), where similar studies for woodland-associated species are rare in the literature (Brouwers \& Newton, 2009c).

Some studies have investigated dispersal of grounddwelling species by fitting regression curves to field data (e.g. Chapman et al., 2007), which is useful as an indicator of the dispersal ability of a species and for making predictions of dispersal range (i.e. distance) over time. A common approach to model and quantify dispersal is to fit a curve to observational data obtained in the field (Turchin, 1998). Curves commonly used to describe the spread of species, such as the fraction of a population moving a certain distance, are often based on equations such as the negative-exponential and inverse-power functions (Turchin, 1998). For some species, observations made in the field were best described by the negativeexponential function (Conrad et al., 1999; Baguette et al., 2000; Baguette, 2003; Kuras et al., 2003; Ranius, 2006; Fric \& Konvicka, 2007), whereas for others the inversepower function was found to provide a better fit (Hill et al., 1996; Baguette et al., 2000; Roslin, 2000; St Pierre \& Hendrix, 2003; Fric \& Konvicka, 2007). The most important difference between these two curves is the behaviour of the tail, where the power function typically predicts a 
higher frequency of long-distance dispersal events than the exponential function (Turchin, 1998). Determining this relationship for a species therefore provides a helpful tool for conservation management.

In order to halt and reverse the effects of species habitat fragmentation, conservation policy and practice is increasingly focusing on the creation of habitat networks (Hobbs, 2002). Networks are typically created through the development of vegetation links or corridors to increase connectivity between individual habitat fragments (Bennett, 2003; Crooks \& Sanjayan, 2006). However, the degree of habitat connectivity within a given landscape is highly dependent on the characteristics of the vegetation and the species being considered (Baguette $\&$ Van Dyck, 2007). Particular vegetated features in the landscape can function either as conduits (i.e. habitat) or barriers to different species (Hobbs, 2002). The role of developing corridors as conduits in terms of facilitating species dispersal still lacks a firm evidence base (Bennett, 2003; Crooks \& Sanjayan, 2006; Bailey, 2007; Öckinger $\&$ Smith, 2008). For example, a recent review of the functioning of hedgerows as possible corridors between woodlands found insufficient empirical evidence to establish their role in facilitating species dispersal (Davies \& Pullin, 2007). Nonetheless, the development of habitat networks utilizing corridors has been widely applied in practice (Hobbs, 2002). In the UK, for example, a large number of initiatives have recently been implemented aiming to reconnect woodland to increase habitat connectivity for woodland species (Humphrey et al., 2003, 2005).

The aim of the study presented here was to investigate the dispersal ability and evaluate the potential of wooded corridors and creating woodland habitat networks in facilitating dispersal for ground-dwelling woodland insects. Research was conducted on the Isle of Wight, UK, where such habitat networks are currently being developed. For this study, two life-stages of a grounddwelling flightless woodland insect, the wood cricket (Nemobius sylvestris), were investigated. The wood cricket was selected for study as it was found to be a good model species representing ground-dwelling insects with a strong association with woodland habitat (Brouwers \& Newton, 2009c, 2010b). Furthermore, it is a local species of conservation concern (NBN Gateway, 2010) that might be expected to benefit from the development of a woodland habitat network, given its association with wooded edges (Richards, 1952; Bailey, 2007; Brouwers et al., 2010).

The specific objectives of this study were: (1) to investigate the differences in dispersal ability observed for wood cricket nymphs and adults (males and females) at a range of spatio-temporal scales within a wooded landscape; (2) to model population spread (i.e. derive the best-fit dispersal curve) for wood cricket nymphs, adult males and females; and (3) to determine to what extent wood crickets disperse along edge habitat outside woodland within an agricultural landscape. This study specifically adopted a range of small to large spatio-temporal experiments, to allow comparison with observations and earlier results for wood crickets found at small spatiotemporal scales (2-25 min, 15-16 $\mathrm{m}^{2}$ ) (Brouwers \& Newton, 2010b). Based on these earlier findings it was hypothesized that: (a) wood cricket adults would show a higher dispersal ability than wood cricket nymphs, as adults showed a more directed movement strategy than nymphs (Brouwers \& Newton, 2010b), (b) wood cricket males and females show similar levels of dispersal ability, as no differences in movement strategy was found between the sexes (Brouwers \& Newton, 2010b), and (c) dispersal distances achieved over a given time would be further along mature woodland habitat edges than along hedge edges or along new woodland plantings, based on observations made in earlier investigations of wood crickets showing a habitat preference for mature woodland edges (Brouwers \& Newton, 2009a, b).

\section{MATERIAL AND METHODS}

\section{Study species}

Wood cricket (Nemobius sylvestris) (Orthoptera: Gryllidae) (Bosc, 1792) is a small $(\sim 1 \mathrm{~cm})$ flightless cricket species that has a semi-voltine (i.e. two-year) life cycle in the UK. After overwintering, eggs hatch in June/July and nymphs develop and grow throughout the summer and autumn by means of moulting up to 5 times from the $1^{\text {st }}$ to the $5^{\text {th }}$ instar stage. Moulting ceases completely in September and the nymphs overwinter at sheltered locations within thick leaf litter layers. In the second year, nymphs continue to develop ( $5^{\text {th }}-8^{\text {th }}$ instar) from April onwards until they reach sexual maturity (i.e. become adults) in July/August and reproduce through to September/October until they die (Gabbutt, 1959; Brown, 1978). The species is generally associated with deciduous oak (Quercus spp.) dominated woodlands and, being a thermophilic insect, is typically found in wooded edge habitat along woodland tracks, footpaths, railway lines and woodland peripheries, and in relatively sheltered open woodland areas such as clearings (Richards, 1952; Morvan \& Campan, 1976; Beugnon, 1980). Wood crickets live on the ground and prefer a well-developed leaf litter layer, which serves as shelter, food source and breeding ground (Richards, 1952; Brown, 1978; Proess \& Baden, 2000). In natural populations wood crickets can be found in high densities at relatively small spatial scales (up to 200 individuals per square meter) (Gabbutt, 1959). At the landscape scale, the species was found to be associated primarily with relatively large woodland patches that were situated in close proximity to each other (Brouwers \& Newton, 2009b). The main habitat requirements and preferences identified for this species were presence of a thick leaf litter layer, an open canopy and low cover of ground vegetation (Brouwers \& Newton, 2009a, 2010b). Adult wood crickets were found to move with a higher velocity and a more directed strategy through leaf litter than juveniles (i.e. nymphs) (Brouwers \& Newton, 2010b). Furthermore, small watercourses were found not to act as a dispersal barrier, and their orientation capacity was found to play a possible important role in their ability to disperse within fragmented landscapes (Brouwers \& Newton, 2010a). This information was used to formulate the hypotheses and inform the design of the experiments that were undertaken in this study.

\section{Study site}

The study was carried out in the Briddlesford area $\left(50^{\circ} 42^{\prime}\right.$ $41.00^{\prime \prime} \mathrm{N}, 1^{\circ} 13^{\prime} 30.50^{\prime \prime} \mathrm{W}$ ) situated on the Isle of Wight (UK) which is owned by "The People's Trust for Endangered 
Species" (PTES), a non-governmental conservation organization. Natural populations of wood crickets are present across this area. The majority of woodlands in this area are classified as "ancient woodland" and are dominated by native deciduous tree species, particularly pedunculate oak (Quercus robur), with undergrowth of hazel (Corylus avellana). Since 2005, extensive new plantings of native tree species have taken place in this area in order to increase connectivity between the individual woodland fragments to create functional habitat networks.

\section{Materials}

In 2007, a series of experiments were conducted investigating the dispersal ability of the wood cricket using nymphs (6- $7^{\text {th }}$ instar) and adult males and females. For the experiments, both nymphs and adults were caught using a pooter. This is a device that is used to collect insects by sucking them into a hold container. Before being released, caught individuals were kept in a plastic container $(21 \times 33 \times 20 \mathrm{~cm})$ with ample supplies of food (bread, various fungi, and oak leaf litter). To increase the visibility of individual wood crickets that were released during the experiments, individuals were marked by dusting them with non-toxic fluorescent pigment (UV Gear, Mark SG Enterprises, Surrey, United Kingdom, www.uvgear.co.uk) (following Cronin, 2003). Marking was achieved by placing individuals in a plastic container with a small amount of pigment, and shaking the container gently until all specimens were marked sufficiently. To investigate the influence of the marking pigment, a control study was performed observing 20 marked and unmarked nymphs and adults within a plastic container $(21 \times 33$ $\times 20 \mathrm{~cm}$ ) continuously for the first $2 \mathrm{~h}$ and then at intervals of $24 \mathrm{~h}$ for 5 days. This study revealed no changes in behaviour and no mortality for either group.

At all experimental site locations, vegetation measurements were carried out using a $50 \times 50 \mathrm{~cm}$ quadrat, measuring (1) ground vegetation cover (in \%) and height (in cm), (2) leaf litter cover (in \%) and depth (in $\mathrm{cm}$ ), and (3) canopy closure (in \%) using a convex spherical densiometer (Forest Densiometers, Bartlesville, US). All experiments were conducted under similar meteorological conditions where mean daytime temperature did not drop below $15^{\circ} \mathrm{C}$.

\section{Enclosure experiment}

To measure population spread of wood crickets over time and distance, five circular enclosures with different diameters were created within an oak-dominated forest stand. The enclosures ranged in size from 2-7 $\mathrm{m}$ radius. For nymphs enclosures of 2, 3, 4 and $5 \mathrm{~m}$ radius were used and, because of their observed higher movement velocity (Brouwers \& Newton, 2010b), an additional $7 \mathrm{~m}$ radius enclosure was created for adults. The enclosures were constructed from $50 \mathrm{~cm}$ high translucent sheet plastic inserted $5 \mathrm{~cm}$ into the ground. The interior habitat of the individual enclosures was homogenized by clearing the ground surface of most of its herbaceous vegetation, resulting in a mean ground vegetation cover of $10 \%$ (range 5-20\%), a mean vegetation height of $10 \mathrm{~cm}$ (range $5-10 \mathrm{~cm})$, and a mean litter cover of 99\% (range $95-100 \%$ ), $3 \mathrm{~cm}$ deep (range $2-3.5 \mathrm{~cm}$ ). The mean overhead canopy closure for all sites was $90 \%$ (range $85-96 \%$ ). These particular habitat characteristics were found to be positively linked with the presence of wood cricket populations (Brouwers \& Newton, 2009a). The initial design included pitfall traps at regular intervals along the inside of the enclosure walls to derive an accurate rate of dispersal (Vermeulen, 1994). A pilot release of wood crickets revealed a low level of mortality over time, and that, unlike ground beetles, wood crickets were able to avoid being caught by pitfall traps. Therefore, the pitfall traps were removed during the actual experiments. Although the pitfall design failed, observations made over the first $48 \mathrm{~h}$ after release, both in the pilot study and the actual experiment, revealed that individuals reaching the circumference of the 3-7 $\mathrm{m}$ enclosures remained at the same locations and numbers accumulated over this period of time. Therefore, observations made during the surveys in the first $48 \mathrm{~h}$ of the experiment (further described below) were used to estimate the rate of dispersal and derive differences in dispersal ability for this species.

At the centre of each enclosure, 50 wood cricket nymphs were released simultaneously at noon on the $11^{\text {th }}$ of June. A second release was conducted for adult wood crickets on the $31^{\text {st }}$ of July, in this case releasing 20 adult males (M) and 20 females (F). The release was achieved by inverting a circular transparent plastic container $(21 \times 10 \mathrm{~cm})$, including the wood crickets and a small amount of leaf litter, in the centre of the enclosures and releasing the specimens after $15 \mathrm{~s}$. After the initial release, continuous observations of the released population within the smallest enclosure ( $2 \mathrm{~m}$ radius) took place for the duration of 1 $\mathrm{h}$. Following this period, all the enclosures were surveyed five times for five successive hours by walking slowly outside the enclosures examining the leaf litter inside the enclosure for presence of marked wood crickets. To account for the difference in chance of observation, the surveys were performed using a constant walking speed for all enclosures. During the following four days, all enclosures were similarly surveyed at $24 \mathrm{~h}$ intervals. Within each enclosure, the number, sex, location, distance between observed males and females, and distance from the enclosure periphery was recorded for each individual observed. For both experiments, the weather was predominantly dry with occasional showers and a mean ground surface temperature of $15^{\circ} \mathrm{C}$.

\section{Analyses}

Because individuals were found to accumulate and remain at the circumference of the 3-7 m enclosures (see Enclosure experiment and Table 1), but not after, only data collected in the first $48 \mathrm{~h}$ after release were used in the analyses. To investigate the differences in dispersal ability for wood cricket nymphs, adult males and females (i.e. individuals observed moving the straight-line distance of the enclosure radius over time); differences between the number of: (i) nymphs and adults, (ii) males and females, and (iii) female vs. male-female pairs (being individuals less than $5 \mathrm{~cm}$ apart) were tested with chi-square "goodness of fit" tests. All individuals that travelled the radius distance from the release point and were observed less than $10 \mathrm{~cm}$ away from the enclosure peripheries were included in these analyses. Furthermore, pairs were compared with single females, because of their assumed attraction to males. To compare the differences between nymphs and adults, the observed numbers were corrected for the difference in the total sample size used [nymphs $(n=200)$ and adults $(n=160)]$. Additionally for nymphs and adults the rate of dispersal was calculated and differences tested between nymphs and adults and males and females with an independent samples t-test were.

To model the population spread of wood cricket nymphs, adult males and females, the proportion of the released population observed at the periphery was calculated. The numbers observed over the first 48 h (i.e. 2 days) were used to calculate the proportions of the populations moving in meters per day $(\mathrm{m}$ day $\left.^{-1}\right)$. For this calculation, individuals of the released populations moving from the release point to the enclosure periphery on the first day (for all enclosures), and the additional number reaching the periphery on the second day $(2-5 \mathrm{~m}$ enclosures for nymphs, 3-7 m for adults) were used (see Table 1). For each enclosure, these proportions were plotted against the straightline distance from the point of release (i.e. the enclosure radius). 
TABLE 1. The number of wood cricket nymphs and adults observed at the enclosure peripheries for the separate enclosures over four consecutive days. Each enclosure contained a population of 50 nymphs or 20 adult male and 20 female wood crickets.

\begin{tabular}{|c|c|c|c|c|c|c|c|c|c|c|c|c|}
\hline \multirow{2}{*}{$\begin{array}{c}\text { Time } \\
\text { Radius }\end{array}$} & \multicolumn{3}{|c|}{$24 \mathrm{~h}$} & \multicolumn{3}{|c|}{$48 \mathrm{~h}$} & \multicolumn{3}{|c|}{$72 \mathrm{~h}$} & \multicolumn{3}{|c|}{$96 \mathrm{~h}$} \\
\hline & $\mathrm{N}$ & $\mathrm{M}$ & $\mathrm{F}$ & $\mathrm{N}$ & $\mathrm{M}$ & $\mathrm{F}$ & $\mathrm{N}$ & $\mathrm{M}$ & $\mathrm{F}$ & $\mathrm{N}$ & $\mathrm{M}$ & $\mathrm{F}$ \\
\hline 2 & 14 & 12 & 7 & 17 & 9 & 6 & 12 & 10 & 7 & 10 & 18 & 9 \\
\hline 3 & 6 & 5 & 3 & 15 & 12 & 6 & 9 & 8 & 9 & 12 & 10 & 7 \\
\hline 4 & 6 & 7 & 1 & 12 & 9 & 5 & 9 & 8 & 4 & 7 & 8 & 3 \\
\hline 5 & 6 & 2 & & 8 & 2 & 1 & 5 & 3 & & 8 & 3 & 2 \\
\hline 7 & & 1 & & & 4 & 1 & & 4 & & & 2 & \\
\hline Total & 32 & 27 & 11 & 52 & 36 & 19 & 35 & 33 & 20 & 37 & 41 & 21 \\
\hline T Adults & \multicolumn{3}{|c|}{38} & \multicolumn{3}{|c|}{55} & \multicolumn{4}{|c|}{53} & \multicolumn{2}{|c|}{62} \\
\hline
\end{tabular}

Radius - radius of the enclosures in meters; $\mathrm{N}$ - nymph; $\mathrm{M}$ - adult male; $\mathrm{F}$ - adult female; $\mathrm{T}$ Adults - total number of adults.

Simple linear regression and the negative-exponential $\left(y=\mathrm{ae}^{-\mathrm{kx}}\right)$ and inverse-power regression functions $\left(\mathrm{y}=\mathrm{ax}^{-\mathrm{n}}\right)$ were used to fit these data for nymphs, all adults, males and females. In these cases, $y$ indicates the proportion of the population moving as a function of: scaling constant (a); distance travelled in meters $(\mathrm{x})$; and parameters determining the slope of the regression $(\mathrm{k}$ and $\mathrm{n})$. Best-fit of these functions was demined by investigation of the residuals following Pallant (2007). All statistical analyses and curves were evaluated using output generated with SPSS (Version 14.0, SPSS Inc., Chicago, Illinois, USA) following Tabachnick \& Fidell (2001) and Pallant (2007).

\section{Dispersal surveys in the landscape}

To determine to what extent wood crickets moved/dispersed along edge habitat outside woodland within the agricultural landscape, marked wood cricket nymphs and unmarked adults were released and monitored over time in three different habitats represented by linear wooded features at six locations within the landscape (i.e. 2 replicates per wooded edge habitat). Absence of the species at the monitoring sites was established during two surveys conducted prior to performing this study. This ensured that the observations that were made could only be that of released individuals. On the $26^{\text {th }}$ of June 50 wood cricket nymphs and on the $3^{\text {rd }}$ of August another 100 adult wood crickets (sex ratio $=0.5$ ) were released at each location. The six release sites were located at the exact L-junctions of linear landscape features running away from a main body of woodland, being (i) a $10 \mathrm{~m}$-wide strip of mature woodland, (ii) a $3 \mathrm{~m}$-wide mature hedge, and (iii) a mature hedge with $3 \mathrm{~m}$-wide strips of newly planted tree saplings along each side. The $1 \times 1 \mathrm{~m}$ release sites were prepared in a similar fashion as the enclosures, representing favourable habitat conditions for wood crickets (see above). The specific edge habitats represented: (1) mature woodland bordering grazed grassland (WE), (2) mature hedges bordering grazed grassland (HE), and (3) ungrazed semi-natural grassland with newly planted saplings bordering grazed grassland (JE). Further habitat characteristics of these edges are given in the results. Additionally, semi-natural and grazed grassland (vegetation height: $15-30 \mathrm{~cm}$, and cover: $100 \%$ ) adjacent to occupied woodland edges was also surveyed. After release, the two edges running away from each release site (situated in the corner of the L-junctions) were surveyed for three consecutive days and re-surveyed four times, sixty days after the initial release of the nymphs. The survey procedure involved walking slowly along or through the different edge habitats in a systematic manner up to $80 \mathrm{~m}$ from the release sites. Individuals were found based on actual sightings of marked and unmarked specimens or the sound of stridulating males, following the survey method of Proess \& Baden (2000). Five-minute listening periods were taken at 5-m intervals along the edge to complement the visual searches. Where specimens were observed or heard, straight-line distances from the point of release and/or the occupied woodland edge were measured. All surveys were of 30-40 min duration and were undertaken under dry weather conditions with a mean daytime temperature of $15^{\circ} \mathrm{C}$ or higher. To indicate to what extent wood crickets were able to move/disperse along edge habitat present within the agricultural landscape, the observed dispersal distances were compared between the different edge habitats using Mann-Whitney $U$ tests in SPSS.

\section{RESULTS}

\section{Enclosure experiment}

Compared to nymphs, adult wood crickets appeared to move in a more directed (i.e. linear) manner, moving mainly by walking. In the first five hours, adults were observed to spread out gradually from the point of release. After the first $24 \mathrm{~h}$ following release, males were heard stridulating within the enclosures and over time $(0-96 \mathrm{~h})$ males and females were increasingly observed in pairs. Contrary to the nymphs, after $96 \mathrm{~h}$ the adults were absent from the release site.

In general, the number of nymphs and adults observed at the periphery decreased with an increase in enclosure size (Table 1). Furthermore, the number of nymphs and adults observed at the periphery of each enclosure increased in the first $48 \mathrm{~h}$ and then levelled off (Table 1), because individuals started to move back into the interior of the enclosures after $48 \mathrm{~h}$. For the adults, all first arrivals at each individual enclosure periphery were males, and on every survey day, the total number of males that was observed was higher than the number of females (Table 1). Furthermore, except for one female, only males were observed at the periphery of the $7 \mathrm{~m}$ enclosure, together indicating a lower dispersal ability/tendency for females than males.

\section{Nymphs vs. adults}

The total number of nymphs observed at the $2-5 \mathrm{~m}$ enclosure peripheries was found to be no different then the number of adults after $24 \mathrm{~h}$ (Chi-square: Nymphs $=16$ vs. Adults $=23, \chi^{2}=1.256, \mathrm{df}=1, P=0.262$ ) and after $48 \mathrm{~h}$ (Chi-square: Nymphs $=26$ vs. Adults $=31, \chi^{2}=$ 0.439 , df $=1, P=0.508)$. This indicates that both life stages show a similar dispersal ability/tendency, therefore rejecting hypothesis (a). 

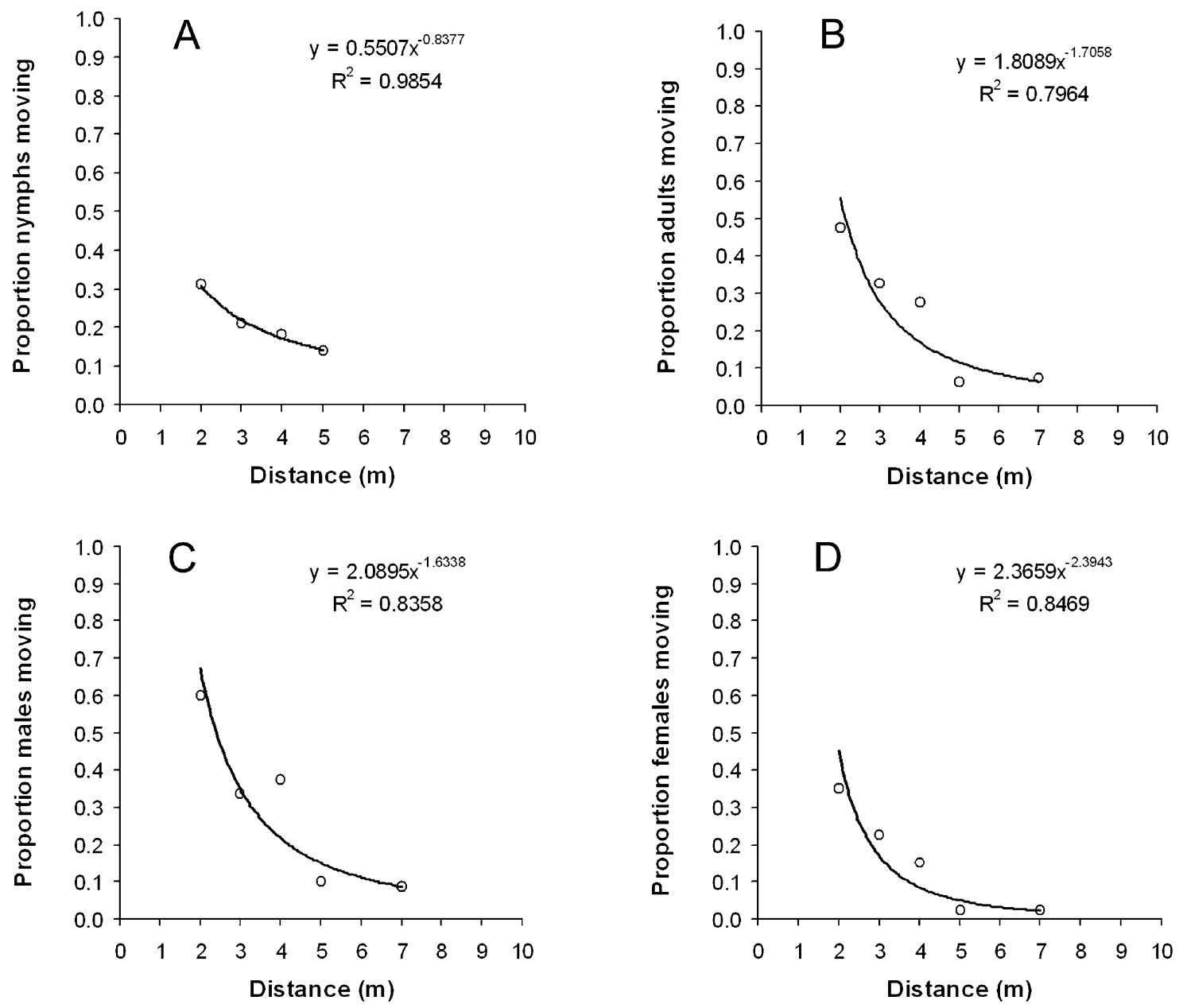

Fig. 1. The proportion of wood crickets moving per day fitted against straight-line distance from the release point. A - nymphs $(n$ $=50$ for each distance/enclosure); $\mathrm{B}-$ all adults $(n=40) ; \mathrm{C}-$ males $(n=20) ; \mathrm{D}-$ females $(n=20)$. Circles indicate the proportion of the population observed that reached the periphery (i.e. dispersed) within each enclosure (i.e. distance) over 24 h. Inverse-power function is fitted to the data. $\mathrm{y}=$ proportion of the population moving, $\mathrm{x}=$ distance $(\mathrm{m})$.

\section{Males vs. females}

Male wood crickets were observed twice as often at the periphery of the 3-7 m enclosures than females both after $24 \mathrm{~h}$ (Chi-square: Male $=15$ vs. Female $=4, \chi^{2}=6.368$, $\mathrm{df}=1, P=0.012)$ and $48 \mathrm{~h}$ (Chi-square: Male $=27 \mathrm{vs}$. Female $\left.=13, \chi^{2}=4.900, \mathrm{df}=1, P=0.027\right)$. This indicates a higher ability and/or tendency for dispersal by males, therefore rejecting the second hypothesis (b). Additionally, the number of male and female pairs within the enclosures increased over time. Overall and over time (i.e. after $72 \mathrm{~h}$ ), the number of pairs was significantly

TABLE 2. Chi-square "goodness of fit tests" for differences between the number of wood cricket female $(n=100)$ and male $(n=100)$ pairs $(\mathrm{F}+\mathrm{M})$ and single females $(\mathrm{F})$ observed at the enclosure periphery over time, for the 2-7 $\mathrm{m}$ enclosures together.

\begin{tabular}{cccccc}
\hline Time & $\mathrm{F}+\mathrm{M}$ & $\mathrm{F}$ & $\chi^{2}$ & $\mathrm{df}$ & $P$ \\
\hline $24 \mathrm{~h}$ & 6 & 5 & 0.091 & 1 & 0.763 \\
$48 \mathrm{~h}$ & 11 & 8 & 0.474 & 1 & 0.491 \\
$72 \mathrm{~h}$ & 15 & 5 & 5.000 & 1 & 0.025 \\
$96 \mathrm{~h}$ & 16 & 5 & 5.762 & 1 & 0.016 \\
\hline Total & 48 & 23 & 22.31 & 1 & 0.000 \\
\hline
\end{tabular}

higher than the number of single females observed (Table 2).

\section{Rate of dispersal}

A mean straight-line dispersal rate in $\mathrm{m} \mathrm{day}^{-1}$ was calculated for individuals of the released populations moving from the release point to the enclosure periphery on the first day, and the additional number reaching the periphery on the second day after release. The mean straight-line dispersal rate for nymphs was $2.57 \mathrm{~m} \mathrm{day}^{-1}$ (range: $1.67-3.13, n=52$ ), which was observed for $26 \%$ of individuals from the released populations within the enclosures, indicating that $74 \%$ of individuals dispersed with lower rates or not at all. For $25 \%$ of individuals in the adult population, the mean dispersal rate observed was $2.91 \mathrm{~m} \mathrm{day}^{-1}$ (range: $2.07-3.84, n=40$ ). This higher dispersal rate for adults was however not statistically different from the rate observed for nymphs (Independent samples t-test: $t=1.343, \mathrm{df}=90, P=0.183)$. Males dispersed with a mean rate of $3.15 \mathrm{~m} \mathrm{day}^{-1}$ (range: $2.08-4.00, n=27$ ) and females with a mean rate of 2.42 m day ${ }^{-1}$ (range: $2.06-3.25, n=13$ ), which was observed for $34 \%$ and $16 \%$ of individuals within the released popu- 
TABLE 3. Straight-line dispersal distances $(\mathrm{m})$ recorded for wood crickets along different habitat edges over 60 days.

\begin{tabular}{ccccccccc}
\hline Edge & Median & Range & $n$ & VH & VC & LC & LD & CC \\
\hline WE & 18.7 & $3.8-29.5$ & 17 & $22-47$ & $26-36$ & $64-80$ & $1.8-2.2$ & $82-99$ \\
HE & 3.0 & $1.2-12.0$ & 20 & $12-24$ & $34-100$ & $24-38$ & $1.0-1.5$ & $63-72$ \\
JE & 4.1 & $1.1-8.5$ & 22 & $24-54$ & $62-65$ & $3-15$ & $0.4-0.8$ & $32-38$ \\
\hline
\end{tabular}

Edge: mature woodland bordering grazed grassland (WE), mature hedge bordering grazed grassland (HE), ungrazed semi-natural grassland with newly planted saplings bordering grazed grassland (JE). Median: median straight-line distance for wood crickets. Range: range of straight-line distances recorded. Range of vegetation characteristics present along the edges that were surveyed: VH - mean vegetation height $(\mathrm{cm})$; VC - total vegetation cover (\%); LC - total litter cover (\%); LD - litter depth (cm); CC - canopy closure $(\%)$.

lations, respectively. This indicates higher dispersal rates for males, however this was not found to be statistically different from the rate observed for females (Independent samples t-test: $t=1.758, \mathrm{df}=38, P=0.087)$. Overall, these results indicate that the majority of individuals $(75 \%)$ within wood cricket populations on average disperse less than $3 \mathrm{~m}$ day $^{-1}$.

\section{Modelling population spread}

For nymphs and adults, the proportion of the total population observed at the enclosure periphery per day was plotted against distance (Fig. 1). The negativeexponential curve and the inverse-power curve were found to fit these data best. Based on the $R^{2}$ values, both curves fitted these data well with $R^{2}$ values ranging between 0.78 and 0.97 for the negative-exponential curve, and slightly higher values $(0.80-0.99)$ for the inversepower curve (F-test, $P<0.05$, Fig. 1). However, where only few data points were used, investigation of the residuals are essential to determine the true fit of these curves (Pallant, 2007). The residuals that were shown in the output plot for the negative-exponential curve were unevenly distributed around the central line, which is reason to reject this relationship (Tabachnick \& Fidell, 2001; Pallant, 2007). The even distribution of the residuals for the inverse-power curve indicated the best overall fit for these data. Overall, the inverse-power curves for both nymphs and adults all show a rapid decline in the number of wood crickets moving with distance (see Fig. 1). Estimates derived from the inversepower equations (see Fig. 1) indicate that potentially only $3.71 \%$ of nymphs, $0.75 \%$ of adults, $1.08 \%$ males and $0.11 \%$ females within a population are dispersing up to $25 \mathrm{~m}$, indicating a likely low level of dispersal for this species.

\section{Dispersal surveys in the landscape}

Wood crickets were found to move furthest along mature woodland edges (Mann-Whitney $U$ : WE vs. HE, $U=22, Z=-4.510, P<0.01$ and WE vs. JE, $U=28, Z=$ $-4.504, P<0.01$, Table 3), confirming hypothesis (c). Over time, wood crickets were observed to move more than two or three times as far along mature woodland edges than along hedge edges and new woodland plantings respectively (Table 3). Distances recorded along the hedge edges and new woodland plantings were not significantly different (Mann-Whitney $U$ : HE vs. JE, $U=$ $167, Z=-1.335, P=0.182$ ). The difference between the edge habitats was also reflected in the habitat characteris- tics. The dispersal distance decreased with a decrease in litter cover (LC), litter depth (LD) and canopy cover (CC) (Table 3), indicating a relationship with these habitat characteristics also found in an earlier study on wood cricket presence (Brouwers \& Newton, 2009a). Additionally, wood cricket males $(n=17)$ were also found in semi-natural and grazed grassland $2.5-55.0 \mathrm{~m}$ away from occupied woodland edges.

\section{DISCUSSION}

In this investigation, we acquired novel information on the dispersal ability of wood crickets at a range of spatiotemporal scales. Studies using different spatio-temporal scales of investigation have been undertaken for mobile insects (e.g. Baguette, 2003; Purse et al., 2003; Keyghobadi et al., 2005), but generally are still lacking (Turchin, 1998), in particularly for ground-dwelling woodland related insect species (Brouwers \& Newton, 2010b). Our study highlights the importance of adopting a multi-scales approach. Furthermore, to fully understand the dispersal ability of a species it was found important to consider both juvenile and adult life-stages (Diekötter et al., 2005). In this study, nymphs showed a similar dispersal rate as adults, contrary to earlier findings on the more directed movement strategy of adults that suggested a higher rate of dispersal compared to nymphs (Brouwers \& Newton, 2010b). This is likely to be a consequence of differences in the spatio-temporal scale that was used for the experiments. This result is highly important in terms of inferring their population spread. Using only small spatio-temporal scales to investigate the dispersal ability of a species can therefore be misleading, and for wood crickets, dispersal is therefore most likely to take place both during their juvenile and adult stages. Our results are similar to those obtained for other orthopteran species, such as the dark bush cricket (Pholidoptera griseoaptera) investigated in Switzerland (Diekötter et al., 2005). At large spatiotemporal scales, Diekötter et al. (2005) found no differences in dispersal ability between juveniles and adults of this species. This non-flying cricket species shows an overlap with the preferred habitats of wood crickets (Diekötter et al., 2005; Brouwers \& Newton, 2009a), suggesting that all individual life-stages are important when assessing dispersal of this type of non-flying cricket species.

Another scaling issue was revealed in the comparison of the sexes. In a previous study using experiments performed at a small spatio-temporal scale (i.e. $<8 \mathrm{~m}^{2}, \sim 20$ min observations), no differences were found in the 
movement strategy between adult males and females, suggesting a similar dispersal rate for both sexes (Brouwers \& Newton, 2010b). However, the current study revealed that, when using larger spatio-temporal scales for observation, adult males were found to move further and more quickly than females. This indicates that the scale of investigation influenced the findings for this species, and highlights the importance of investigating dispersal at a range of scales. Differences in dispersal ability between sexes have been observed previously for grasshoppers (Maes et al., 2006); however, for cricket species similar in their habitat preferences to wood crickets this was not observed (Diekötter et al., 2005). Wood cricket males are likely to attract females with their stridulation, as has been found in several other cricket species (Marshall \& Haes, 1988; Simmons \& Ritchie, 1996; Scheuber et al., 2003). In the current study, the increasing number of wood cricket pairs that were observed over time is a likely indication of the influence of this factor. Altogether, this might indicate that adult wood cricket males act as the primary dispersers potentially attracting females with their stridulation. However, this type of speciesspecific trait needs to be investigated more closely to derive its actual influence on dispersal success (Holyoak et al., 2008).

Only a small fraction $(\sim 25 \%)$ of wood cricket nymphs and adults averaged a daily straight-line dispersal rate of $2.9 \mathrm{~m} \mathrm{day}^{-1}$, with the majority of the populations moving with lower velocity. For the bush cricket (Pholidoptera griseoaptera), Diekötter et al. (2005) found that nymphs and adults of this species were equally sedentary, but overall the species showed higher dispersal rates compared to wood crickets. In this case the daily rate was calculated over the first $24 \mathrm{~h}$ using distances observed for all the individuals in the released population, recording mean rates of 1.7-3.8 $\mathrm{m} \mathrm{day}^{-1}$ for juveniles and 3.0-6.3 $\mathrm{m} \mathrm{day}^{-1}$ for adults (Diekötter et al., 2005). For field crickets (Gryllus campestris L.) living in herb-rich meadows, rates were obtained for all males, which moved a mean distance of $2.8 \mathrm{~m} \mathrm{day}^{-1}$ (Ritz \& Kohler, 2007). Considered together these results suggest that, compared to other cricket species for which data are available, dispersal within wood cricket populations is limited, and the species can be considered as relatively sedentary.

Population spread of both adults and nymphs was most accurately described by the inverse-power function. These results are supported by findings in a study conducted on adult wood crickets in France (Morvan et al., 1978). After we performed further analyses on markresight data collected in their study (Morvan et al., 1978), population spread was also found most accurately described by the inverse-power function. The dataset collected by Morvan et al. (1978) was gathered in similar habitat to that of our study. These combined results suggest that the inverse-power function is appropriate to describe the spread for both wood cricket nymphs and adults. The use of the inverse-power equation for describing population spread or dispersal in cricket species that move by walking is supported by results from other studies. For instance, the frequency distribution of the number of two-coloured bush crickets (Metrioptera bicolor) dispersing through their preferred dry grassland habitat environment within a matrix of pine forests and arable land (Kindvall, 1999), correlated closely with the inverse-power relationship. This indicates that the inverse-power equation seems an appropriate tool to describe the spread or dispersal of non-flying cricket species in this type of investigation.

The overall observed limited dispersal distances and population spread achieved by the species through their preferred habitat (i.e. open canopy woodland with leaf litter and sparse ground vegetation) are supported by earlier observations of wood cricket nymphs and adults moving through this type of habitat (Gabbutt, 1959; Morvan \& Campan, 1976; Morvan et al., 1977, 1978). However, the current study also showed that some individual males were able to disperse up to $55 \mathrm{~m}$ away from favourable habitat. This is consistent with a previous mark-recapture experiment within continuous open woodland habitat, where adult wood crickets were shown to be able to disperse up to $60 \mathrm{~m}$ over a period of 30 days (Morvan et al., 1978). These observations together suggest that at least some wood crickets (i.e. males) are able to disperse relatively long distances, with an apparent threshold distance of around $50 \mathrm{~m}$ per year (Brouwers \& Newton, 2010). However, since females show about half the level of dispersal ability compared to males, overall population spread, being female dependent, is therefore likely to be no more than $25 \mathrm{~m}$ per year.

In terms of colonization success of new habitat, this study revealed that over time wood crickets moved most readily along mature wooded edges and less along hedges and immature new plantings within the landscape. Dispersal can however only be successful if suitable edge habitat is available for the species to establish a viable population, as represented along woodland edges. Establishing a woodland habitat network by creating wooded corridors between woodlands might therefore increase dispersal incidence and prove beneficial for the persistence of wood crickets within the wider landscape over time. The positive effect of maintaining linear features within an agricultural matrix in terms of colonization success has been shown in detailed studies on Roesel's bushcricket (Metrioptera roeseli) (Berggren et al., 2001, 2002). Results suggested that these features helped in facilitating dispersal and the persistence of this cricket species within the wider landscape (Berggren et al., 2001, 2002), as also found for Orthoptera occurring in the Bialowieza Forest (Theuerkauf \& Rouys, 2006). For wood crickets, corridor functioning is likely to be highly dependent on its maturity and factors such as tree and ground vegetation cover, leaf litter presence and the geographical orientation of the corridor edges (Brouwers \& Newton, 2009a). Therefore the design and maturity of the wooded corridor will determine if the species is inclined and able to disperse along and through these features, as suggested in other studies (Bennett, 2003; Bailey, 2007). Initiatives focusing on long-term management planning 
and careful designation of locations for woodland habitat networks will further be essential. Given time, the ongoing investment of creating wooded corridors between woodland fragments therefore has the potential to facilitate colonization success and population viability of wood crickets and similar species within the wider landscape.

ACKNOWLEDGEMENTS. We like to thank the Forestry Commission and the Scottish Forestry Trust for funding this research. Furthermore, we like to thank the People's Trust for Endangered Species (PTES) for providing us with the opportunity to work in their woodlands on the Isle of Wight. We also like to thank A. Watt (Centre for Ecology and Hydrology), K. Kirby (Natural England), K. Watts (Forest Research) and three anonymous reviewers for their input and comments on this manuscript.

\section{REFERENCES}

Baguette M. 2003: Long distance dispersal and landscape occupancy in a metapopulation of the cranberry fritillary butterfly. Ecography 26: 153-160.

BAGUETTE M. \& VAN DYCK H. 2007: Landscape connectivity and animal behavior: functional grain as a key determinant for dispersal. Landsc. Ecol. 22: 1117-1129.

Baguette M., Petit S. \& Queva F. 2000: Population spatial structure and migration of three butterfly species within the same habitat network: consequences for conservation. J. Appl. Ecol. 37: 100-108.

BAILEY S. 2007: Increasing connectivity in fragmented landscapes: an investigation of evidence for biodiversity gain in woodlands. Forest Ecol. Manag. 238: 7-23.

Baur B., Coray A., Minoretti N. \& Zschokke S. 2005: Dispersal of the endangered flightless beetle Dorcadion fuliginator (Coleoptera: Cerambycidae) in spatially realistic landscapes. Biol. Conserv. 124: 49-61.

BennetT A.F. 2003: Linkages in the Landscape: The Role of Corridors and Connectivity in Wildife Conservation. IUCN, Gland, Switzerland and Cambridge, UK, $254 \mathrm{pp}$.

Berggren A., Carlson A. \& Kindvall O. 2001: The effect of landscape composition on colonization success, growth rate and dispersal in introduced bush-crickets Metrioptera roeseli. J. Anim. Ecol. 70: 663-670.

Berggren A., Birath B. \& Kindvall O. 2002: Effect of corridors and habitat edges on dispersal behavior, movement rates, and movement angles in Roesel's bush-cricket (Metrioptera roeseli). Conserv. Biol. 16: 1562-1569.

Beugnon G. 1980: Daily migrations of the wood cricket Nemobius sylvestris. Environ. Entomol. 9: 801-805.

Brouwers N.C. \& Newton A.C. 2009a: Habitat requirements for the conservation of wood cricket (Nemobius sylvestris) (Orthoptera: Gryllidae) on the Isle of Wight, UK. J. Insect Conserv. 13: 529-541.

Brouwers N.C. \& Newton A.C. 2009b: The influence of habitat availability and landscape structure on the distribution of wood cricket (Nemobius sylvestris) on the Isle of Wight, UK. Landsc. Ecol. 24: 199-212.

Brouwers N.C. \& Newton A.C. 2009c: Movement rates of woodland invertebrates: a systematic review of empirical evidence. Insect Conserv. Divers. 2: 10-22.

Brouwers N.C. \& Newton A.C. 2010a: The influence of barriers and orientation on the dispersal ability of wood cricket (Nemobius sylvestris) (Orthoptera: Gryllidae). J. Insect Conserv. 14: 313-317.
Brouwers N.C. \& Newton A.C. 2010b: Movement analyses of wood cricket (Nemobius sylvestris) (Orthoptera: Gryllidae). Bull. Entomol. Res. 100: 623-634.

Brouwers N.C., Newton A.C., Watts K. \& Bailey S. 2010: Evaluation of buffer-radius modelling approaches used in forest conservation and planning. Forestry 83: 409-421.

BRowN V.K. 1978: Variations in voltinism and diapause intensity in Nemobius sylvestris Orthoptera Gryllidae. J. Nat. Hist. 12: 461-472.

Chapman D.S., Dytham C. \& Oxford G.S. 2007: Modelling population redistribution in a leaf beetle: an evaluation of alternative dispersal functions. J. Anim. Ecol. 76: 36-44.

Conrad K.F., Willson K.H., Harvey I.F., Thomas C.J. \& SherRATT T.N. 1999: Dispersal characteristics of seven odonate species in an agricultural landscape. Ecography 22: 524-531.

CRONIN J.T. 2003: Movement and spatial population structure of a prairie planthopper. Ecology 84: 1179-1188.

Crooks K.R. \& Sanjayan M. (eds) 2006: Connectivity Conservation. Cambridge University Press, Cambridge, 728 pp.

DAVIES Z.G. \& PUllin A.S. 2007: Are hedgerows effective corridors between fragments of woodland habitat? An evidence-based approach. Landsc. Ecol. 22: 333-351.

Diekötter T., Csencsics D., Rothenbuhler C., Billeter R. \& Edwards P.J. 2005: Movement and dispersal patterns in the bush cricket Pholidoptera griseoaptera: the role of developmental stage and sex. Ecol. Entomol. 30: 419-427.

Diekötter T., Baveco H., Arens P., Rothenbühler C., Billeter R., Csencsics D., De Filippi R., Hendrickx F., Speelmans M., Opdam P. \& Smulders M. 2010: Patterns of habitat occupancy, genetic variation and predicted movement of a flightless bush cricket, Pholidoptera griseoaptera, in an agricultural mosaic landscape. Landsc. Ecol. 25: 449-461.

Dolman P.M. \& Fuller R.J. 2003: The processes of species colonisation in wooded landscapes: a review of principles. In Humphrey J., Newton A., Latham J., Gray H., Kirby K., Poulsom E. \& Quine C. (eds): The Restoration of Wooded Landscapes. Forestry Commission, Edinburgh, pp. 25-36.

FAHRIG L. 2003: Effects of habitat fragmentation on biodiversity. Annu. Rev. Ecol. Evol. Syst. 34: 487-515.

FRIC Z. \& Konvicka M. 2007: Dispersal kernels of butterflies: Power-law functions are invariant to marking frequency. Basic Appl. Ecol. 8: 377-386.

GabButT P.D. 1959: The bionomics of the wood cricket, Nemobius sylvestris (Orthoptera: Gryllidae). J. Anim. Ecol. 28: $15-42$.

HANSKi I.A. \& Gilpin M.E. (eds) 1997: Metapopulation Biology. Ecology, Genetics, and Evolution. Academic Press, New York, $512 \mathrm{pp}$.

Hill J.K., Thomas C.D. \& Lewis O.T. 1996: Effects of habitat patch size and isolation on dispersal by Hesperia comma butterflies: implications for metapopulation structure. J. Anim. Ecol. 65: 725-735.

HoвBs R.J. 2002: Habitat networks and biological conservation. In Gutzwiller K.J. (eds): Applying Landscape Ecology in Biological Conservation. Springer, New York, pp. 150-170.

Holyoak M., Casagrandi R., Nathan R., Revilla E. \& Spiegel O. 2008: Trends and missing parts in the study of movement ecology. Proc. Nat. Acad. Sci. 105: 19060-19065.

Humphrey J., Newton A., Latham J., Gray H., Kirby K., Poulsom E. \& Quine C. 2003: The Restoration of Wooded Landscapes. Forestry Commission, Edinburgh, $158 \mathrm{pp}$.

Humphrey J., Watts K., McCracken D., Shepherd N., Sing L., Poulsom L. \& Ray D. 2005: A Review of Approaches to Developing Lowland Habitat Networks in Scotland. Scottish Natural Heritage, Edinburgh, 90 pp. 
Keyghobadi N., Roland J. \& Strobeck C. 2005: Genetic differentiation and gene flow among populations of the alpine butterfly, Parnassius smintheus, vary with landscape connectivity. Mol. Ecol. 14: 1897-1909.

KindVALL O. 1999: Dispersal in a metapopulation of the bush cricket, Metrioptera bicolor (Orthoptera: Tettigoniidae). $J$. Anim. Ecol. 68: 172-185.

Kuras T., Benes J., Fric Z. \& Konvicka M. 2003: Dispersal patterns of endemic alpine butterflies with contrasting population structures: Erebia epiphron and E. sudetica. Popul. Ecol. 45: 115-123.

LEVIN S.A. 1992: The problem of pattern and scale in ecology: The Robert H. MacArthur Award lecture. Ecology 73: 1943-1967.

Maes D., Ghesquiere A., Logie M. \& Bonte D. 2006: Habitat use and mobility of two threatened coastal dune insects: Implications for conservation. J. Insect Conserv. 10: 105-115.

Marshall J.A. \& Haes E.C.M. 1988: Grasshoppers and Allied Insects of Great Britain and Ireland. Harley Books, Essex, $252 \mathrm{pp}$.

Morvan R. \& Campan R. 1976: Displacement of ground crickets: conditions of acquisition and maintenance of a dominant orientation. (Les déplacements du grillon des bois: conditions d'acquisition et de maintien d'une orientation dominante.) Terre et Vie 30: 276-294.

Morvan R., Campan R. \& Thon B. 1977: The spatial distribution of a population of wood crickets Nemobius sylvestris in its natural habitat - I. The larval population (Etude de la répartition du grillon des bois Nemobius sylvestris (Bosc) dans un habitat naturel - I. Les larves). Terre et Vie 31: 637-660.

Morvan R., CAmpan R. \& Thon B. 1978: The spatial distribution of a population of wood crickets Nemobius sylvestris in its natural habitat - II. The adult population (Etude de la répartition du grillon des bois Nemobius sylvestris (Bosc) dans un habitat naturel - II. Les adultes). Terre et Vie 32: 611-636.

Nathan R. 2008: An emerging movement ecology paradigm. Proc. Nat. Acad. Sci. 105: 19050-19051.

NBN Gateway 2010: National Biodiversity Network Gateway. UK, CEH and JNCC. Available on http://www.searchnbn. net/ (accessed November 2007).

ÖCKINGER E. \& SMITH H. 2008: Do corridors promote dispersal in grassland butterflies and other insects? Landsc. Ecol. 23: $27-40$.

Pallant J. 2007: SPSS Survival Manual. Open University Press, Berkshire, $352 \mathrm{pp}$.

Proess R. \& BADEN R. 2000: Survey of the orthopteran species Barbitistes serricauda (Fabricius, 1798), Leptophyes punctatissima (Bosc, 1972), Meconema thalassinum (De Geer, 1773) and Nemobius sylvestris (Bosc, 1792) in Luxembourg (Insecta, Saltatoria). Bull. Soc. Natur. Luxembourg. 100: $159-170$.
Purse B.V., Hopkins G.W., Day K.J. \& Thompson D.J. 2003: Dispersal characteristics and management of a rare damselfly. J. Appl. Ecol. 40: 716-728.

RANIUS T. 2006: Measuring the dispersal of saproxylic insects: a key characteristic for their conservation. Popul. Ecol. 48: 177-188.

Richards T.J. 1952: Nemobius sylvestris in S.E. Devon. The Entomologist 85: 83-87; 108-111; 136-141; 161-166.

Ritz M.S. \& KoHLer G. 2007: Male behaviour over the season in a wild population of the field cricket Gryllus campestris (L.). Ecol. Entomol. 32: 384-392.

RosLIN T. 2000: Dung beetle movements at two spatial scales. Oikos 91: 323-335.

Samu F., Sziranyi A. \& Kiss B. 2003: Foraging in agricultural fields: local "sit-and-move" strategy scales up to risk-averse habitat use in a wolf spider. Anim. Behav. 66: 939-947.

Scheuber H., JACOT A. \& Brinkhof M.W.G. 2003: Condition dependence of a multicomponent sexual signal in the field cricket Gryllus campestris. Anim. Behav. 65: 721-727.

Simmons L.W. \& Ritchie M.G. 1996: Symmetry in the songs of crickets. Proc. Biol. Sci. 263: 1305-1311.

St Pierre M.J. \& Hendrix S.D. 2003: Movement patterns of Rhyssomatus lineaticollis Say (Coleoptera: Curculionidae) within and among Asclepias syriaca (Asclepiadaceae) patches in a fragmented landscape. Ecol. Entomol. 28: 579-586.

TABACHNICK B.G. \& Fidell L.S. 2001: Using Multivariate Statistics. Allyn \& Bacon, Boston, 966 pp.

Theuerkauf J. \& Rouys S. 2006: Do Orthoptera need human land use in central Europe? The role of habitat patch size and linear corridors in the Białowieża Forest, Poland. Biodivers. Conserv. 15: 1497-1508.

Trakhtenbrot A., Nathan R., Perry G. \& Richardson D.M. 2005: The importance of long-distance dispersal in biodiversity conservation. Divers. Distrib. 11: 173-181.

Tscharntke T., Steffan Dewenter I., Kruess A. \& Thies C. 2002: Characteristics of insect populations on habitat fragments: a mini review. Ecol. Res. 17: 229-239.

TURChIN P. 1991: Translating foraging movements in heterogeneous environments into the spatial distribution of foragers. Ecology 72: 1253-1266.

TuRChIN P. 1998: Quantitative Analysis of Movement. Sinauer Associates, Sunderland, MA, 396 pp.

Turner M.G., GARDNER R.H. \& O'NeILl R.V. 2001: Landscape Ecology in Theory and Practice. Pattern and Process. Springer, New York, 404 pp.

VERMEULEN R. 1994: The effect of different vegetation structures on the dispersal of carabid beetles from poor sandy heaths and grasslands. In Desender K., Dufrêne M., Loreau M., Luff M.L. \& Maelfait J.-P. (eds): Carabid Beetles: Ecology and Evolution. Vol. 51. Kluwer Academic Publishers, Dordrecht, pp. 387-392.

Received August 31, 2010; revised and accepted October 26, 2010 